\title{
LA RETÓRICA DE CRITICAL LEGAL STUDIES. IMPRESIONES DE UN LECTOR ESPAÑOL ${ }^{1}$.
}

\section{Condiciones históricas}

Algunas puntualizaciones sobre la historia reciente de España pueden contribuir a explicar por qué el movimiento CLS no cuenta con defensores en nuestro país. Durante la era de Franco, especialmente hacia el final del régimen, la izquierda española estaba organizada y unificada. Por supuesto, podía encontrarse una extrema izquierda, pero la lucha contra la dictadura era un objetivo común. El asesinato de Carrero Blanco por el grupo terrorista ETA, por ejemplo, fue celebrado por muchos liberales e izquierdistas y considerado el primer paso de la transición hacia la democracia. Sin Carrero Blanco, la transición a la democracia fue más viable.

Esta transición ha sido muy complicada pero finalmente España cuenta con una democracia similar a la de otros países occidentales. Sin embargo, la democracia ha destruido la unidad de la izquierda. Ha dejado al terrorismo fuera de la ley y ha integrado en el sistema a muchos políticos contrarios a Franco. En realidad la izquierda comunista ha perdido progresivamente su poder. Muchos de los comunistas

${ }^{1}$ Estoy especialmente agradecido al profesor David Owen de la Universidad de South Carolina quien me ha aportado comentarios y críticas muy útiles. Duncan Kennedy de Harward Law School y Ann de Moor de Oxford University me han ayudado con sus críticas. He podido beneficiarme de los fondos de investigación n.PB 90-327 y BE 92-39 que la DGTYC ha cedido al departamento de filosofia del derecho de la Universidad Pompeu Fabra 
se han convertido en socialistas. Otros optaron por la izquierda y unos terceros por la derecha. La democracia fue inestable hasta el golpe de estado frustrado de Tejero (1981). Desde entonces la integración de España en Europa y los cambios en la economía la han consolidado.

Hemos alcanzado la democracia pero sabemos qué es una dictadura porque no hemos perdido la memoria. Precisamente porque hemos conocido la dictadura valoramos la democracia y el liberalismo. En el régimen franquista no había tensiones internas entre diferentes concepciones de la justicia institucional, ni diferencias de opinión desde el punto de vista legal autoritario, e incluso en muchos casos, ni siquiera existía distinción entre crimen y pecado. No existía la posibilidad de que el pensamiento crítico tuviera un medio oficial de expresión. Había una ideología institucional impuesta a nivel nacional. El bien y el mal no estaban fundamentados en argumentos sino en la autoridad. Sabemos lo que es la autoridad. Sabemos algo sobre el peligro de un modo de vida ilustrado. En pocos años la democracia y el liberalismo han adoptado valores que la España institucional no había reconocido casi nunca.

El discurso legal y político de los CLS tiene la crítica de las doctrinas liberales como uno de sus objetivos principales ${ }^{2}$. En España existen críticos del sistema y algunos grupos creen que la democracia no es un modo de gobierno justificado. Estos grupos, sin embargo, están divididos y el apoyo con el que cuentan es mucho menor al anterior a la muerte de Franco. Parecen lamentar el cambio a la democracia por la pérdida de poder que ésta ha supuesto para estos grupos.

Estas son algunas razones que explican el por qué el movimiento CLS no cuenta con simpatizantes en España. Pero no son las únicas. Sugeriré algunas críticas sobre las posiciones y tesis de los Criticals.

\section{Algunas observaciones personales}

Estoy muy interesado en la filosofía del derecho anglosajona. He introducido en España obras de autores americanos como por ejemplo Dworkin, Calabresi, Polinski o Lyons. Respeto y admiro la filosofía

${ }^{2}$ Neil MacCormick sostiene que «muchas de las afirmaciones de los CLS no parecen ir mucho más allá de una imaginativa idea del estado de bienestar occidental», en Reconstruction after Deconstruction: A Response lo CLS. Oxford Journal of Legal Studies vol. 10, 1990, pág. 539. Creo que esta aserción es falsa. Los CLS presentan un programa ambiguo y contradictorio. Ver A. Altman Critical Legal Studies: A Liberal Critique. Princenton University Press, 1990, el último capítulo. 
anglosajona. En ocasiones mis colegas me han acusado de simpatizar en exceso con el pensamiento americano. Para los adolescentes de nuestro país, América es la tierra prometida. Parece que todo lo que procede de América es bueno. Esta idea es errónea. En la filosofía del derecho también es errónea. Se pueden encontrar argumentos buenos y malos en la filosofía anglosajona. A pesar de mi interés por la filosofía del derecho americana, sólo recientemente he dedicado mi atención al movimiento CLS.

Los comentarios que a continuación sugeriré expresan los sentimientos e impresiones que un lector español experimenta cuando empieza a leer artículos y tesis de los Criticals.

No quisiera dar la impresión de que he leído todos los libros y artículos sobre CLS, pues no es cierto. En 1989 el profesor Hutchinson dijo que se habían publicado alrededor de 700 artículos tras diez años de trabajo. No pude leer todos estos artículos, lo cual significa que tal vez puedan encontrarse lagunas en mis impresiones. El segundo punto que me gustaría dejar claro es la irregularidad en la calidad de los trabajos. En algunos casos un lector español honesto tiene la impresión de no formar parte del público con el que los críticos buscan comunicarse. En tercer lugar apuntaría que, a pesar de que los CLS se quieren presentar como movimiento, es difícil determinar sus características porque diferentes autores piensan cosas diversas sobre los mismos temas ${ }^{3}$.

\section{El discurso político}

Los españoles somos muy sensibles al discurso político porque estamos construyendo una nueva democracia y estamos dejando atrás siglos de intolerancia y conservadurismo. El discurso crítico se presenta como discurso político antiliberal. Pero paradójicamente no está claro qué otra forma de gobierno es mejor que la democracia y el liberalismo. Los partidarios del movimiento CLS critican la democracia pero su proyecto político es débil, y parece estar cerca de slogans como «pesimista en el intelecto y optimista en la voluntad». Pero estos lemas no tienen ningún

${ }^{3}$ Se han hecho muchos esfuerzos para unificar el movimiento. Ver los libros de: R. Unger: The Critical Legal Studies Movement, Harvard University Press, (2 ed.) 1986. A Hutchinson (ed): Critical Legal Studies, Totowa, Bowman y Littelfield, 1989, y M. Kelman: A Guide to Critical Legal Studies, Harward Univesrity Press, 1987. Ver A. Hunt: Reading Dworkin Critically, New York y Oxford, Berg Publishers, 1992. Hunt sostiene que la unidad del movimiento CLS está en crisis y que «las divergencias internas de la tradición de los CLS deben confrontarse más abiertamente en la actualidad». (pág. 4) 
sentido como alternativa política e ideológica ${ }^{4}$. Creo que hay una gran indefinición en este tema ${ }^{5}$.

La situación política de España, al igual que la académica, es diferente a la de Estados Unidos. En España el marxismo gozó de mucho predicamento en los años sesenta y setenta. Este y el neomarxismo ocupan un lugar en la academia. Los liberales no persiguen a los marxistas porque ambos tienen un pasado común en la lucha contra la dictadura. Hay personas que consideran que el marxismo no constituye un sistema de ideas adecuado para gobernar la sociedad pero no existe una reacción en contra del marxismo. En otras palabras, no existe actualmente la «cruzada» en este país como la hubo durante el régimen de Franco contra el marxismo y el liberalismo. Hace veinte o treinta años era difícil pertenecer al cuerpo académico sin compartir una cierta ideología de derechas. De vez en cuando las autoridades cometían errores y se les introducía alguien que no compartía la ideología oficial. En general se puede decir que la academia estaba controlada por las autoridades gubernamentales y no por los académicos. Por supuesto que pueden cometerse injusticias en cualquier academia, pero sabemos exactamente qué es la persecución. Sabemos y apreciamos la libertad de expresión porque nos fue prohibida durante mucho tiempo. Somos reacios a renunciar a ciertos valores. Los defensores de los CLS son en su mayoría americanos que no pueden apreciar tanto el valor de la democracia como lo hace un país a quien le ha sido prohibida históricamente.

El discurso de buenos y malos es similar al discurso de los CLS. El liberalismo es malo; los CLS son buenos. El liberalismo -desde su perspectiva- se presenta como un anacronismo político peligroso, aunque los regímenes totalitarios y autoritarios son peores desde mi punto de vista.

El objetivo de los CLS es la crítica del liberalismo. El liberalismo no ha prestado demasiada atención al desafío del movimiento de los CLS ${ }^{6}$. Los criticals acusan al liberalismo de «autocontradictorio» ${ }^{7}$.

${ }^{4}$ Ver Alan Hutchinson, op. cit., pág. 10.

${ }^{5}$ Ver Mark Tushnet: Critical Legal Studies: Introduction to its Origins and Underpining, Journal of Legal Education, vol. 36, 1986, pág. 516: «la implicación más importante del análisis dominante de los CLS es que cualquier crítica del orden existente es consistente con el proyecto de los CLS». El programa de crítica indeterminable es el único importante. Vid pág. 510, en donde reconoce que el movimiento «CLS... no cuenta con un programa constructivo».

${ }^{6}$ Ver R. Dworkin: Law's Empire, Belknap, 1986, pág. 271 s. Ver también N. MacCormick: Reconstruction after Deconstruction: a Response to CLS. OJLS vol. 10. J. Finnis: On the Critical Legal Studies Movement, en J. Ekelar et al. Issues in Legal Philosophy. Oxford University Press, 1991.

${ }^{7}$ Ver Alan Hutchinson, op. cit., pág. 4 y sig. 
Kelman ha realizado una síntesis de las principales críticas al liberalismo. Sostiene que es un sistema de pensamiento bloqueado por contradicciones internas y por la represión de estas contradicciones. La primera de ellas se encuentra entre normas y principios; una segunda entre el valor subjetivo y objetivo y la tercera entre el discurso intencionalista y el determinista ${ }^{8}$.

En este trabajo estudiaré su retórica y un aspecto de la contradicción general. Sostendré que los Criticals son escépticos y que subestiman la relación que el liberalismo ha creado entre los individuos y la comunidad. Sin duda, el Estado del bienestar se encuentra con problemas en algunas áreas, tales como la legitimidad, la representación o la exclusión del pensamiento. Pero a pesar de estos problemas, creo que todavía no se ha presentado una alternativa no utópica. Para la democracia es fundamental que los utópicos la critiquen, y el discurso crítico es importante como discurso alternativo, pero los Criticals no proponen un modelo para cambiar y reconstruir el Estado 9 . En este sentido los Criticals juegan un papel parecido al de los realistas que mantuvieron un programa crítico del Estado liberal sin un método de análisis objetivo. Los realistas argumentaron que los resultados legales estaban controlados por los sentimientos e intuiciones de los jueces. Pero los realistas sabían exactamente qué opciones políticas defendían. El realismo se centraba en la política del «New Deal», pero ¿cuál es la agenda política de los CLS ${ }^{10}$ ¿Cuál es la herramienta de los CLS?

\section{CLS: ¿se pueden tomar en serio?}

Soy un profesor europeo y no estoy muy familiarizado con la historia interna de la jurisprudencia americana y quizás por ello tengo una idea equivocada de los CLS. Puedo leer a los autores de CLS pero sólo desde mi bagaje intelectual, lo cual condiciona mi punto de vista. Mi primera reacción al analizar los CLS es no tomármelos muy en serio debido a lo sorprendente de algunas de sus tesis. Tengo la impresión de

${ }^{8}$ Ver Mark Kelman: A Guide to Critical Legal Studies, op. cit., pág. 3.

${ }^{9}$ Vid Robert Unger: Critical Legal Studies Movement op. cit., págs. 36 y sigs., en el cual diseña su programa superliberal en las áreas de gobierno, economía y derechos. Reconoce explícitamente que su programa político es débil en las últimas páginas de este trabajo.

${ }^{10}$ Vid. R. Unger: Critical Legal Studies Movement, op. cit.: «representa un gran esfuerzo intentar que la vida social se asemeje todavía más a lo que la política es en las democracias liberales». 
que los defensores de los CLS están bromeando y presentan algunas tesis a modo de diversión. Aportaré dos o tres ejemplos para demostrarlo ${ }^{11}$.

Estoy de acuerdo con el profesor Alan Hutchinson cuando dice que «cualquier partidario de CLS merece ser tratado por sus méritos y hablar en su propio interés... la caricatura no debe tener lugar ${ }^{12}{ }^{2}$, pero los CLS han negado este ideal porque han creado un concepto de liberalismo que nadie en el mundo del liberalismo defendería. La caricatura es exagerada. Los Criticals no se caracterizan por su respeto intelectual hacia aquellas teorías que critican.

El problema no se encuentra sólo en la caricatura sino también en el lenguaje análogo de los adolescentes ${ }^{13}$, el cual es de difícil comprensión para un extranjero.

Duncan Kennedy ha escrito lo siguiente en su programa educativo:

«Cada estudiante podrá hablar ad libitum -continuar hablando. No importa. Ningún estudiante debe responder a lo que dice otro estudiante porque esto es inconsistente con la idea de que los valores son subjetivos, individuales y personales para que alguien diga: «mira, eres un charlatán, cállate». Esto sería inconsistente con el enfoque de radical subjetivismo de los valores. Así cualquiera puede decir cualquier cosa durante el tiempo que desee. No hay necesidad de que nada se corresponda con nada- una reacción que podría interpretarse como mi discurso, mis valores son correctos, los tuyos erróneos» ${ }^{14}$.

Louis Schwartz ${ }^{15}$ ha escrito que Duncan Kennedy hizo una propuesta defendiendo la abolición del sistema de adjudicación de cátedras, la admisión en la escuela de Derecho a suertes y la discusión en clase estructurada de tal manera que diera más tiempo a los estudiantes pobres o menos preparados para expresar sus pensamientos y ser escuchados. Estas ideas se incluyeron en el informe del comité de planificación educacional y desarrollo de la Harvard Law School. No sé si esto es verdad o se trata simplemente de una broma. Lo que si sé es que no puedo considerarlo seriamente.

${ }^{11}$ Ver Louis Schwartz: With Gun and Camers: Through Darkest CLS Land Stanford Law Review, vol. 36, 1984. Schwartz critica duramente el movimiento CLS y demuestra que es una fuente de confusión. Concluye su artículo afirmando que los CLS nos ofrece imágenes surrealistas.

${ }^{12}$ Ver A. Hutchinson op. cit., pág. 1.

${ }^{13}$ Ver, por ejemplo, el artículo de Duncan Kennedy: Roll over Beethoven, Stanford Law Review, vol. 36, 1983-84.

${ }^{14}$ Citado por L Schwartz, op. cit., 419.

${ }^{15}$ Ibid, pág. 413. 
Hay otras propuestas incomprensibles: la alternancia de modo rotativo de los puestos de trabajo: por ejemplo: un día bedel y otro decano. Tal vez mi incomprensión se deba a que el sentido del humor español -y en especial el catalán- sea distinto, o quizás no podemos entender la política académica y los argumentos que se esconden tras esta propuesta, pero estas ideas no tienen sentido para nosotros.

El ámbito de las propuestas de los Criticals no se reduce a la reforma educativa, sino que también tienen algo que decir en el terreno espistemológico. Alan Hutchinson sostiene, por ejemplo, que «una demostración de coherencia racional y de contradicción es fatal sólo dentro de la tradición epistemológica liberal racionalista» ¿Cuál es el sentido de esta «tesis»? ¿Por qué cambia el valor de un argumento según quien lo afirme? «Toda la tradición epistemológica liberal racional -sostiene Hutchinson- se debe desacreditar y desmantelar. Como en la célebre disputa entre Galileo y el poder establecido en Italia, no se trata meramente de la verdad de la naturaleza sino también de modificar la naturaleza de la verdad $\rangle^{16}$. Los CLS intentan presentar un criterio nuevo para distinguir el saber correcto del incorrecto. Pero ¿cuál es el nuevo saber? Los CLS pretenden construir una nueva epistemología para rechazar la liberal, pero proponen el subjetivismo radical como criterio epistemológico. Galileo tenía una propuesta constructiva. No puedo entender la pretensión de que uno pueda ser incoherente por el solo hecho de no ser liberal. Sin un lenguaje común es imposible hablar y argumentar. Los Criticals mantienen que el lenguaje liberal no es adecuado, pues ellos emplean otro. Sin embargo, los argumentos son difíciles de entender si el lenguaje no es común. En otras palabras, parece haber una contradicción entre la subjetividad del valor, por una parte, y la pretensión de discutir y debatir como académicos, por otra ${ }^{17}$.

${ }^{16}$ Ver Hutchinson, op. cit., pág. 5

${ }^{17}$ En contra de esta interpretación ver A. Altman: Critical Legal Studies: A Liberal Critique, op. cit. Altman sostiene que el diálogo entre liberales y Criticals puede resultar productivo. Ver también J. M. Balkin: Taking Ideology Seriously: Ronald Divorking and the CLS Critique. University Missouri Kansas Law Review, vol. 55, 1987. Balkin critica a Dworkin porque «no presta atención a los efectos de la ideología en la formación de conceptos legales y de métodos de razonamiento jurídico... Por esta razón los miembros de los CLS tienen mucho que aprender de la obra de Dworkin, la cual trata de temas que los CLS han subestimado». Ver también A. Hunt (Ed): Reading Dworkin Critically, op. cit., pág. 3, en la cual afirma que parte de la izquierda «empieza a tomarse el liberalismo en serio». En contra de esta tesis ver A. Hutchinson: The Last Emperor? pág. 49 donde sostiene que «el factor unificador de este grupo electoral es su oposición a la dominación intelectual y política del establecimiento liberal» 
Los CLS reivindican que deben ser tomados en serio, pero para ello es necesario que consideren también seriamente los puntos de vista de sus interlocutores. Parece que los Criticals no acaban de entender el papel que juegan los argumentos y los subordinan a la fe, lo cual se demuestra en su frecuente cambio de posición. Eso confunde al lector. En sus textos encuentro más slogans que argumentos ${ }^{18}$.

Muchas de las tesis de los Criticals me parecen falsas. Por ejemplo: la teoría legal y la jurisprudencia se identifican con la descripción y justificación del papel que juega la administración de justicia en una democracia (Hutchinson). El alcance de la jurisprudencia es mucho más amplio que la adjudicación. Los juristas están preocupados por la estructura de los sistemas legales normativos. ¿Acaso es la adjudicación el tema central y más importante de la teoría de Hart o de Kelsen? La preocupación por la adjudicación ocupa un lugar importante en América, pero no es la única. La jurisprudencia también se ocupa de la descripción del sistema legal y de la construcción de conceptos básicos.

Otro argumento a discutir es el siguiente: «Las personas dedicadas al pensamiento jurídico siempre han sido individuos pertenecientes a las clases dominantes. Los juramentos implícitos de lealtad siempre han formado parte de los requisitos para ingresar en los círculos jurídicos»» ${ }^{19}$. El liberalismo siempre ha recibido críticas, tanto de la derecha como de la izquierda. Este slogan parece falso. En España ha habido muchos abogados en contra del status quo y la lealtad no siempre se ha respetado. Un ejemplo de esto lo constituye la lucha que muchos abogados llevaron a cabo contra la dictadura. La transición a la democracia de los países del Este es otro ejemplo. La lealtad implícita de los abogados hacia el status quo es un slogan falso. Los ejemplos pueden extenderse a movimientos judiciales tales como «jueces para la Democracia» o la «Magistratura Democrática» italiana.

Otras ideas que se presentan como radicalmente nuevas -tales como la crítica al formalismo-, no lo son. El segundo Ihering, los realistas, Gény, Schmitt y tantos otros han criticado el formalismo y la autonomía del pensamiento jurídico. El movimiento «Uso alternativo del diritto» en Italia hizo una crítica similar con una mezcla semejante de argumentos y con consecuencias políticas contradictorias con su ideología.

${ }^{18}$ Esto se hace patente en las proposiciones de Unger. De Knowiedge and Politics a las últimas obras se registran algunos cambios. ¡Desde la refutación al liberalismo y desde éste al superliberalismo! Ver William Ewald: Unger's Philosophy: A Critical Legal Study. The Yale Law Journal, vol. 97, 1988. Págs. 753 y sigs. Ver en la misma revista las críticas de Cornell West en las que denuncia la rotura epistemológica de Unger.

${ }^{19}$ Ver D. Kennedy: The Structure of Blackstone's Commentaries, Buffalo Law Review, núm. 28, 1979, pág. 218. 
Es posible que el formalismo constituya únicamente un «espantapájaros» ya que son pocas las teorías que defienden el formalismo estricto ${ }^{20}$. ¿Quién es formalista según el modelo de los críticos? ¿Lo son acaso Dworkin, Raz o Finnis? ${ }^{21}$ El formalismo depende del contexto, porque en algunos escritos las teorías interpretativas pueden resultar formalistas. Sin embargo, éste es un concepto inusual de formalismo que induce a confusión. Gran parte de la retórica de los CLS es una confusión. ¿Los CLS han propuesto un nuevo método que permita resolver el problema del formalismo? Los defensores del análisis económico del derecho han ideado un sofisticado método para analizar y solventar las disputas. Dworkin ha propuesto un nuevo método que permite el análisis y que puede ser útil para decidir problemas, pero ¿cuál es el método de los CLS? ¿El negativismo sin explicación? No llego a descubrir cuáles son las herramientas que proponen para analizar y solucionar problemas. Únicamente encuentro quejas y, eso sí, muchas palabras.

Los Criticals son escépticos pero no explican por qué el escepticismo es una idea atractiva en filosofía y política. Sus argumentos sobre el pensamiento jurídico parecen dudosos. Kennedy afirma que «es imposible discurrir sobre el sistema legal sin un esquema de categorías», pero seguidamente añade que «todos estos esquemas son falsos. Limitan y perturban nuestra experiencia inmediata y lo hacen, no de un modo fortuito o casual, sino sistemático ${ }^{22}$. ¿Cómo sabe que los esquemas son falsos? ¿Quizá es que sabe la Verdad? ¿Dónde se halla su escepticismo? Más tarde sostiene que los esquemas de categorías tienen una vida por si mismas. Entiendo sus slogans, pero no puedo vislumbrar la persuasión de sus argumentos.

Los Criticals se apropian el descubrimiento de contradicciones entre los intereses del individuo y la colectividad ${ }^{23}$. Pero no se trata de una novedad. La teoría liberal reconoce que se dan contradicciones entre los intereses de los individuos y los de la comunidad. ¿A caso los problemas del free rider no han sido analizados por los liberales? ¿Creen los liberales que los valores son objetivos? ¿En qué sentido?

${ }^{20}$ Ver G. Tarello: L’Interpretazione della legge. También, K. Larenz, Metodología de la Ciencia del Derecho, Barcelona, Ariel, 1980, apéndice.

${ }^{21}$ De alguna manera lo son si aceptamos la definición de Unger.

${ }^{22}$ Ver D. Kennedy: The Structure of Blackstone's Commentaries; op. cit., pág. 215.

${ }^{23}$ Ver D. Kennedy: The Structure of Blackstone's Commentaries op. cit., pág. 211 y sigs. en la cual sostiene que la idea de la gran contradicción es la idea clave para entender el derecho porque es la esencia de todos los problemas. D. Kennedy no sugiere ninguna razón que explique la incompatibilidad entre individuo y comunidad. La presupone. D. Kennedy aparece como dogmático cuando sostiene que el pensamiento jurídico es un mecanismo para negar la contradicción. 
¿Existe alguna relación entre el relativismo y el liberalismo? ¿Están los CLS usando el objetivismo de un modo distinto al convencional? ¿Por qué hablan de «contradicción» como lucha entre intereses en contextos donde la contradicción está normalmente relacionada con la contradicción lógica? ¿Por qué razón emplean el término «formalismo» de un modo distinto al del discurso moral filosófico ${ }^{24}$ ¿Por qué usan el término «liberalismo» en un sentido extraño ${ }^{25}$

Los Criticals atribuyen a los liberales ideas que generalmente éstos no defienden. Por ejemplo: los liberales creen que existe injusticia, pobreza y desigualdad en la sociedad occidental. No tiene sentido pensar que los liberales justifican el status quo. Es sorprendente que los CLS afirmen la autoconfianza del liberalismo e identifiquen liberal con legitimador del sistema. Muchos liberales piensan que existe mucha injusticia en nuestras sociedades.

Los CLS parecen haber descubierto que realmente existe una relación entre derecho y política. Pero, ¿ha negado alguien esta relación? ¿Llewellyn? ¿Kelsen? ¿Hart? ¿Dworkin? La relación entre ambos es tan reconocida que resulta asombroso considerarlo un descubrimiento. ${ }^{26}$

Los Criticals mantienen que su innovación metodológica ${ }^{27}$ está fundamentada en una mezcla de marxismo y realismo. «Lo mejor de los CLS -dice Alan Hutchinson- es que son autoconscientes de sus puntos de vista y combinan ingredientes neomarxistas y neorrealistas con el fin de obtener un apetitoso pastel de jurisprudencia, esperando que atraiga y satisfaga el apetito popular»». ${ }^{28}$ Es verdad que la gente

${ }^{24}$ Por ejemplo R. Unger en su The Critical Legal Studies Movement, op. cit., la pág. 1 quien después de aceptar el significado convencional de formalismo sostiene que el formalismo en este contexto en «un compromiso, y por lo tanto la creencia en la posibilidad de un método de justificación legal que contraste con las disputas sin fin sobre los términos básicos de la vida social, disputas que se llaman ideológicas, filosóficas o visionarias». D. Kennedy llama formalismo a un sistema de pensamiento que relaciona algunas formas de intervención colectiva, tales como la defensa de la propiedad privada y la observancia de los contratos, con la protección de la libertad individual. Ver su artículo The Structure of Blackstone's Commentaries, op. cit. pág. 214.

${ }^{25}$ Ver D. Kennedy. The Structure of Blackstone's Commentaries, op. cit pág. 214.

${ }^{26}$ Ver, por ejemplo H. Hart: The Concept of law, Oxford University Press, 1961, págs, 197-207. Ver R. Dworkin: A Matter of Principle. Harward University Press, 1985, pág. 1 en la cual explica que su libro trata de la interacción entre estos dos niveles de nuestra conciencia política: los problemas prácticos y la teoría filosófica, asuntos de urgencia y de principio.

${ }^{27}$ En uno de sus mejores artículos Duncan Kennedy mantiene que su método puede considerarse estructura lista, fenomenológico o neomarxista, o, incluso, los tres a la vez. The Structure of Blackstone's Commetaires, op. cit., pág. 209.

${ }^{28}$ Ver A. Hutchinson, op. cit., pág. 6. 
consume discurso fundamentalista y dogmático, lo cual tal vez explica el limitado éxito de los Criticals. Pero puede argüirse que el neomarxismo de los Criticals es extraño porque las principales tesis de Marx se encuentran enmascaradas. Los CLS parecen no entender la esencia del pensamiento marxista. Quizá sus posiciones puedan ser consideradas marxistas light. De todas maneras, se encuentran lejos del marxismo estudiado por los europeos.

Los Criticals defienden que los CLS constituyen un fenómeno exclusivamente americano. Esto es cierto. En Europa es difícil aceptar o entender su aparente ignorancia del pensamiento político europeo y su inexplicable intolerancia para con otros puntos de vista ${ }^{29}$. No nos gusta jugar con la irracionalidad porque sabemos cuáles son sus consecuencias. Si los Criticals conocieran las tradiciones europeas hubieran reparado en que la mayoría de sus ideas ya fueron expresadas por el ideólogo nazi C. Schmitt, como por ejemplo la censura del liberalismo y el neutralismo, la exaltación de la irracionalidad, las irreconciliables contradicciones entre intereses, la apelación a una autoridad que decida sin límites, la idea de que la teoría es un arma para destruir al enemigo y, finalmente, la defensa de una autoridad que se deja llevar por su propia concepción de la moralidad como intérprete supremo del espíritu de la comunidad.

Si los CLS hubieran considerado su posición desde un punto de vista político se hubieran dado cuenta de que la irracionalidad en política es un factor peligroso que cuenta con mucho apoyo, y que teorías fundamentalistas o intolerantes pueden acabar cautivándonos. En este sentido puede considerarse la nueva ola de racismo en Europa o el fundamentalismo en los países islámicos. No nos gusta bromear con la irracionalidad en política porque las experiencias históricas nos han enseñado sus consecuencias.

Finalmente, los Criticals proponen abolir las normas y dar prioridad a los principios $^{30}$. La contradicción ${ }^{31}$ interna de los principios, cuyo

${ }^{29}$ R. Unger menosprecia los trabajos de la escuela de análisis económico del derecho diciendo que «cuando llegamos eran como el clero que ha perdido su fe y no obstante ha mantenido sus puestos». The Critical Legal Studies Movement op. cit. pág. 119.

${ }^{30}$ Ver M. Kelman, op. cit., pág. 63, en la cual afirma que las reglas son el opio de las masas. En su Guía, Kelman presenta a los Criticals de una manera académica, pero de vez en cuando la tentación de la retórica le lleva a incluir frivolidades. ¿Es posible que la propuesta de eliminar las normas llegue a ser una propuesta políticamente práctica en nuestra sociedad? ¿Cómo puede implementarse con el programa de que las ramas del gobierno tienen que multiplicarse? Ver R. Unger, op. cit. pág. 32 .

${ }^{31}$ Ver D. Kennedy: Form and Substance in Private Law Adjudication Harward 
descubrimiento se atribuyen, les permite desenmascarar la gran mentira del liberalismo. Creo que formalistas como Kelsen y otros no tan formalistas como MacCormick y Bobbio también han localizado este problema. La dialéctica entre un argumento contrario y uno favorable no constituye un descubrimiento reciente. La retórica no nos permite avanzar. La Teoría General del Derecho hace muchos años que se enfrenta a este problema.

\section{¿Es atractivo el movimiento CLS?}

Los Criticals se han esforzado en poner en claro las injusticias y el descontento que generan de la sociedad y el derecho contemporáneos. Creo que el manifiesto es útil como terapia contra el exceso de confianza y autosatisfacción del pensamiento jurídico. Estoy de acuerdo con el descontento pero no con el pesimismo del intelecto ni con el escepticismo ${ }^{32}$.

El desafío más interesante es el escepticismo. Los Criticals encuentran contradicciones y sostienen que el material no se puede reorganizar de manera que resulte interesante. Su actitud se asimila a la del hombre primitivo que no entiende los fenómenos de la naturaleza, que no encuentra ninguna lógica y no hace ningún esfuerzo por entender el mundo que le rodea. Creo que lo mejor que puede hacer es no hacer nada. Los Criticals se parecen a este hombre primitivo, porque defienden la irracionalidad del mundo. La incapacidad del intelecto debe ser solventada por la voluntad. Entonces la voluntad no quiere reconstruir nada, sino actuar sin razón.

Frente a la actitud derrotista, el hombre primitivo puede intentar buscar una explicación. Primero la religión fue el sistema de explicación. Más tarde lo fue la filosofía. $\mathrm{Y}$, finalmente, la ciencia. Si observamos el mundo y la naturaleza sin preguntas no podemos ver nada. Los Criticals mantienen que todo es irracional porque no comprenden que la ciencia es constructiva, que la ciencia es algo inventado por los hombres y las mujeres para entender el universo. $\mathrm{Y}$ en el mundo moral y político sostienen que los hombres y mujeres no pueden encontrar valores objetivos. Luego, si no hay valores naturales, no hay valores

Law Review, 89, 1976, donde sostiene que las normas armonizan con el individualismo y los standards con el altruismo.

${ }^{32}$ Vid R. Unger. op. cit., pág. 8: «puesto que todo puede defenderse nada puede defenderse» 
objetivos. El mundo es un caos y dentro del caos no existe racionalidad alguna.

El escepticismo de los CLS no es sólo externo -en el lenguaje de Dworkin- sino también interno. Creen que es mejor destruir que construir, que es mejor desenmascarar la religión que considerar que tal vez a través de ella se transmita algún saber valioso. Gracias a la religión el hombre se planteó preguntas y propuso respuestas -a menudo incorrectassobre muchos problemas. La transición de la religión a la filosofía no fue sólo crítica sino también constructiva. Creo que desde un punto de vista epistemológico la destrucción es terapéutica pero que nuestro saber ha progresado gracias a las aportaciones de los constructivistas. Si el hombre primitivo hubiera sido crítico, quizás estaríamos viviendo en cavernas. El descontento con el pensamiento actual es desafiante, pero el pesimismo del intelecto es frustrante.

Otro reto importante es la oposición entre individualismo y altruismo. El individualismo se define como insistencia en definir y alcanzar los objetivos personales propios sin ayuda exterior. La esencia del altruismo reside en que uno no debería conceder más importancia a sus propios objetivos que a los de los demás. El altruismo nos ordena hacer sacrificios, compartir y ser benevolentes con los demás ${ }^{33}$. Kennedy sostiene que las normas son individualistas y que los standards son altruistas. Es difícil estar de acuerdo con esta afirmación, pues existen actividades que no se pueden llevar a término sin un cierto grado de cooperación. Creo que las normas son relevantes más allá del individualismo. Tocar en un cuarteto, por ejemplo, requiere la cooperación de los cuatro componentes. Los intereses de los demás no son siempre contradictorios con los intereses individuales. La cooperación permite satisfacer preferencias individuales. Aquí no hay contradicción entre individuos y la colectividad.

Pero incluso si aceptamos la contradicción no hemos llegado a una solución del problema inicial. En realidad, Kennedy sostiene que el individualismo es malo porque los individuos deberían poder comportarse en contra de sus propios intereses. El punto de vista individualista mantiene que las personas son los mejores jueces de sus propios intereses. Kennedy es partidario del personalismo y sostiene que las normas paternalistas no deberían ser excepcionales. El problema entonces es quién debe determinar y quién tiene derecho a mandar sobre las personas. Kennedy debe apoyar algún tipo de argumento autoritario y totalitario: si no eres capaz de persuadir a la gente, entonces debes

${ }^{33}$ Vid D. Kennedy: Form and Substance in Private Law Adjudication op. cit., págs. 39 y sigs. 
forzarla a ser libre y altruista. Este es el argumento de la dictadura que Kennedy parece apoyar a través de sus afirmaciones acerca de la irracionalidad de los valores individuales ${ }^{34}$ y de su promoción de un programa utópico del colectivismo sin jueces ni Estado ${ }^{35}$.

Tengo la impresión de que el individualismo se identifica con experiencias placenteras. Pero en realidad, los hombres y las mujeres parecen preferir vivir en una sociedad con una estructura que respete los derechos humanos. Y ésta es una preferencia individual. Se tiene que aceptar que los objetivos colectivos son el resultado de las preferencias individuales. El liberalismo puede ser considerado un individualismo no estricto, como, por ejemplo, el que sostiene Raz en su obra Morality of Freedrom.

Mis dudas acerca los CLS podrían resumirse en los siguientes puntos:

1. Reconozco, al igual que la mayoría de los liberales, que el liberalismo no es perfecto como sistema político. ¿Cuál es la alternativa política al liberalismo? ¿Escepticismo o superliberalismo? ¿Cuáles son los medios para alcanzarlo?

2. ¿Qué posición defienden los Criticals desde el punto de vista epistemológico? ¿Cuáles son los criterios de verdad? ¿Se puede distinguir entre tesis correctas e incorrectas, o no existen criterios?

3. ¿Cómo opera el Derecho si no existen normas? ¿Realmente es posible gobernar una sociedad con standards? Sin normas, ¿cómo funcionan los seguros y la regulación del tráfico? «altruistas»?

4. ¿Qué razones justifican que las normas sean «individualistas» y los standards

5. ¿Por qué se basan en el marxismo? ¿En qué sentido son marxistas los Criticals? ¿Es la revolución la manera de resolver la injusticia? ¿Qué significa el «optimismo de la voluntad»?

6. ¿Qué significa «contradicción»? ¿Cuáles son los argumentos filosóficos que justifican el escepticismo?

7. ¿Qué herramientas ofrecen y utilizan los Criticals?

${ }^{34}$ Vid D. Kennedy: Form and Substance in Private Law Adjudication, op. cit., pág. 50 en la cual afirma que «el postulado de la arbitrariedad de los valores significa que no hay base para discutirlos. Incluso dando por supuesto que los valores son objetivos... sería imposible mostrar mediante ningún proceso racional cómo se puede cambiar esta situación (objetiva)». El autor atribuye esta ideología al individualismo.

${ }^{35}$ Ibid, pág. 53 


\section{¿Paradigmas distintos?}

Los Criticals no están de acuerdo con las premisas del liberalismo. Creo que una de sus tesis principales la constituye el conflicto irreconciliable entre individuos y sociedad. $\mathrm{Si}$ este punto se mantiene, no existe posibilidad de diálogo porque las cuestiones que presenta el liberalismo son, desde el punto de vista de los Criticals, absurdas.

Los liberales reconocen que hay individuos con intereses personales, por un lado, y la sociedad, por otro. La primera discusión que surge es si existe algún tipo de acuerdo social que permita la existencia de una sociedad justa. El liberalismo mantiene que esta idea merece apoyo y que existe la posibilidad de una sociedad bien diseñada. Los liberales no son escépticos. Creen que se puede conseguir algún tipo de arreglo social justo. Los liberales sientan las premisas de su discurso político sobre esta asumida relación entre individuo y sociedad. Los liberales creen que «la gran contradicción» puede resolverse y que su misión es buscar una respuesta a esta pregunta. En otras palabras, creen en la posibilidad de un diseño de una sociedad con individuos que tienen derechos.

Los Criticals ofrecen su apoyo al escepticismo porque la «gran contradicción» existe. Las creencias de los liberales son consideradas parte de la ideología que enmascara la contradicción. Los Criticals no sólo piensan que el paradigma liberal es inadecuado, sino que también argumentan que los liberales son inmorales. Atribuyen mala fe a los liberales porque construyen un paradigma que enmascara la situación real de contradicción. La segunda ola de feminismo ${ }^{36}$ también está de acuerdo con este paradigma escéptico. Las feministas radicales creen que no existe una solución al problema que se plantea entre el individuo y la sociedad. Las leyes de la sociedad son las leyes de los hombres. Las mujeres no quieren ser iguales a los hombres. Creen que la contradicción del sexo es la gran contradicción, igual que la contradicción de clases lo es en el marxismo ${ }^{37}$.

La cuestión que los Criticals quieren resolver tiene una respuesta muy distinta a la de los liberales. Por esta razón, el diálogo resulta, cuanto menos, difícil. El desafío de los Criticals es el escepticismo. No hay mediación entre individuos y sociedad. Entonces, no existe la posibilidad de una sociedad justa en la cual los individuos tengan derechos.

${ }^{36}$ Ver C. MacKinnon: Feminism, Marxism, Method and the State: Towards Feminist Jurisprudence, Signs, 1983.

${ }^{37}$ Ver A. Hutchinson, op. cit., pág. 4: «El emperador judicial... decide y actúa con el fin de proteger y preservar el interés del poder masculino que reviste» 
El segundo paso de los liberales es de tipo técnico. Si estamos de acuerdo en los valores de una sociedad justa, ¿cuáles son los mecanismos para alcanzar los objetivos? ¿Pueden diseñarse los mercados e instituciones privadas o públicas?. Dentro del liberalismo existe necesariamente alguna forma de mercado, pero hay también diversos modos de organización de estos mecanismos. Este segundo paso sólo tiene sentido si el primero ha gozado de un cierto éxito. Si se cree que la relación entre individuos y sociedad es contradictoria, y que la justicia moral no es posible, el segundo tema no tiene ningún interés.

No es posible contra argumentar inmediatamente a la gran contradicción de los Criticals con la premisa liberal de que un acuerdo de justicia social puede ser alcanzado a través de otros acuerdos. Según los CLS, o los individuos destruyen la comunidad o la comunidad destruye a los individuos. En ambos casos nos encontramos en el mundo de la utopía o defendiendo un acuerdo autoritario ${ }^{38}$. O somos anarquistas, y entonces no contamos con reglas sociales, o somos totalitarios y entonces no existen los individuos. La debilidad de la teoría crítica resulta de la debilidad de sus propuestas políticas. El escepticismo no puede hablar; sólo puede suspender el juicio. El escepticismo no puede construir teorías; sólo puede destruirlas. El escepticismo no puede ofrecer un modelo de sociedad con individuos, pero, ¿puede dar apoyo a una utopía autoritaria?

Mi lectura de CLS puede ser errónea y mis impresiones pueden ser el resultado de una interpretación incorrecta de sus ideas. Espero obtener alguna respuesta por su parte que me permita formar una mejor imagen de sus teorías. Creo que su trabajo representa un desafío y que sirve como estímulo para una discusión más profunda en el campo del criticismo. En el balance final me encuentro con dudas sustanciales respecto a la posibilidad de construir algo con resultados positivos empleando sus herramientas conceptuales.

${ }^{38}$ D. Kennedy escribió en Form and Substance in Private Law Adjudication: «La libertad del individualismo es enajenada y arbitraria... sólo se puede alcanzar la libertad real colectivamente a través de la autodeterminación. Somos demasiado débiles para decidir aislados. Cierto, la autodeterminación colectiva, una clase de utopía, implica el uso de la fuerza contra el individuo. Pero sufrimos y aceptamos el uso de opresión física y psíquica en la vida familiar cotidiana, en la educación, en la cultura...» 